\title{
Centering on the Passengers - the Airline Internet Strategy Analyses
}

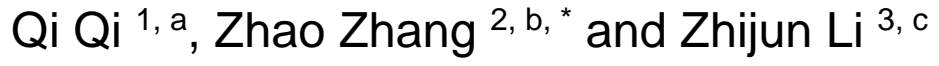 \\ ${ }^{1}$ No.10 Xiangyun West Street Baiyun Airport, Guangzhou, China \\ ${ }^{2}$ No.7, Yumin Street, Shunyi Dist., Beijing, China \\ ${ }^{3}$ No.2550, Hongqiao Road, Changning District, Shanghai, China \\ a qiqi@caac.net, ${ }^{*}$, b zhangzhao@travelsky.com, c zhjli@ceair.com
}

Keywords: Focus on passengers, Airlines, Internet, Channel Strategic, and IT Infrastructure.

\begin{abstract}
Based on the analysis of the the airline Internet level at this stage, the paper puts forward that "Centering on the passengers" is the basis of the airlines' Internet. For airlines, the final result of the Internet must be realized human-human interconnection, human-machine interconnection, human-material interconnection, machine-material interconnection. How to achieve airlines Internet? This article pertinently point out four aspects: understanding internet users, and defining the Internet products, layout of the Internet channel, and building the Internet IT system, which constitute the airlines implementation path for centering on the passengers. Finally, they have been upgraded to new airlines with the internet characteristics of high efficiency, synergy, openness, employee egodrive, excellent experience for passengers, and high proportion of value-added income, and etc.
\end{abstract}

\section{Introduction}

According to the new ages changes, new ages trends and new ages requirements, internationalization and Internet have begun to be the common direction of social and enterprise development in the new era. From the service integration strategy, internationalization strategy, to Internet strategy today, the airline giants are steadily push forward all works to make the company to gain greater market opportunities in the future. The author tries to analyze and think about the airlines Internet strategy with the view of "centering on passengers" at the present stage.

\section{Analyzing the Airlines Internet at the Present Stage.}

At present, the Internet development has entered into the second half. In the past ten years, there have been many enterprises that have developed through "Internet", typical representatives are: Tencent, Alibaba, Google, etc. Tencent has made internet on the traditional communication methods, and Alibaba has made Internet on the traditional wholesale and retail methods. Google has made internet on the people's traditional way of acquiring knowledge. As the Internet grew into the second half, the growth of Internet users began to slow, and in this case, it was time to start looking for new business directions. In the second half of the Internet ages, the new technologies are emerging, such as: Artificial Intelligence, Augmented Reality, Virtual Reality, Internet of Things(IOT), etc., these technologies will have a revolutionize upgrade in the Internet infrastructure, which will cause some great changes.

Under the internet background, the airlines has invested to develop the "e-commerce" system, for instance, realizing the products be sold on the Internet and mobile phones, and self check-in function. At this stage, the airlines were taking advantage of the Internet to optimize and innovate the air tickets sale and business process, so as to avoid the pressure from the channels, a significant increasing in direct selling proportion, by 2017, some airlines even broke through the 50\% proportion of direct selling.

From the global level, the old brand airlines also took action, for example: the Royal Dutch airline was using the social media for marketing activities and service propaganda, to obtain the recognition from more passengers; IATA, the international air transport association (IATA), launched the NDC (New Distribution Capacity) standard, and its ultimate goal is to make the traditional distribution 
model be change to internet model. The airline's strategic focus has become effort to shift the consumer spending from distribution channel to direct channel, and the Internet has made the transition feasible and the cost controllable.

\section{Centering on the Passengers is the Airlines Internet Foundation.}

Since 2007, domestic airlines have been launching in succession B2C websites and mobile apps, while vigorously promoting passenger self-service, such as airport self check-in, online check-in and mobile check-in. Since then, these Internet applications have been constantly updated, and today travelers can access the Internet at 10,000 meters high altitude. Airlines have begun to see initial success on the Internet. Throughout those successful companies in the Internet era, , whether Tencent or Alibaba, or Apple or Xiaomi, have the biggest characteristics-- "user-centric". Regardless of platform establishment, product design, sales and delivery, which all around users , always to reach the users' maximize satisfaction as the ultimate goal. For airlines, the Internet final result must be realized human-human interconnection, human-machine interconnection, human-material interconnection, machine-material interconnection, as shown in the picture below:

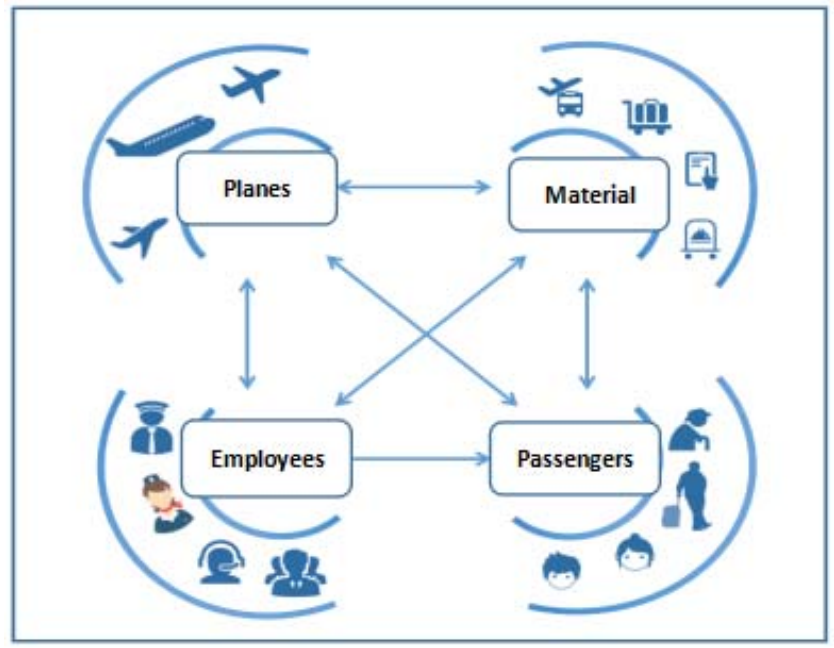

Figure 1. Airlines Internet Schematic Diagram

As you can see from this picture, internet airlines could realize the interconnection between the people and objects in the internal and external company, the "people" are the most fundamental driving force source, the people here include: staffs and passengers. After the airlines internet success, which will effectively implement among staffs, passengers, aircraft, and using the hardware or software during the air transport business processes in the seamless connectivity, so as to realize the efficient coordination of the work flow and passenger service quality improvement.

Therefore, The goal of the airlines internet should be to build a collaborative and efficient operation system through the in-depth application of the Internet infrastructure to create the excellent travel experience for passengers. its goal is more efficiently obtain passengers, to ensure sustained growth in revenue from the main business, while ensuring the revenue of ancillary services. Draw lessons from the thinking mode of some successful business on the Internet age, combined with the characteristics of the airline's main business, the author considers that: the main line of the Internet is to build a business processes with "Centering on the passengers". Only with such a common thread to lead each business unit of the airline Internet, to make the airline internal formed as a whole together power in the process of Internet and finally achieved the airlines Internet strategy.

\section{The Realizing Path for the "Centering on the Passengers"}

Before airlines reached the "internet", its mainly sales model depends on the distribution channels to sell tickets, when passengers boarded the plane, the airlines company got their first chance to get in touch with the travelers, and to understanding "zero" about the passengers' consuming habits, and 
activity habits. Airlines began to try the "internet" in 2007, set up their own website and APP, to realize to build a connection with passengers in the travel preparation stage, to implement the airline through the site or the mobile terminal access to users' data and to unearth passengers' behavior. For example, how many days in advance are the passengers used to searching the tickets before the trip started on a site, what time will use the online check-in function before departure, etc., in terms of this analysis which provides an extremely guidance to the airline Internet .

First of all, understanding the Internet travelers. Setting up the passenger grouping and evaluating the passengers' value, the airlines could give each passenger a CV Value (Customer Value) which is calculated by classical RFM model. At any time, as long as according to a passenger's CV Value that could be roughly judge this passengers is how importance for the airlines, so as the airlines can continue to improve the passenger experience, adjust the products supply strategies, enhance the quality of offline services, etc.

Secondly, defining the internet-based products. At the initial stage of the airlines development , the product form was very simple. Passengers can only pay a fee, buy the seats on the selected flight, and then go to the airport. In the $1990 \mathrm{~s}$, the airline brought in the subclass control method, the revenue management theory was get to start application, to quantify for the passenger travel demand forecasting, formed in different time stages before departure sales prices are different sales way . Let's look at the Air Canada's website, when a passenger searches for a flight from Beijing to vancouver, as shown in the picture below.

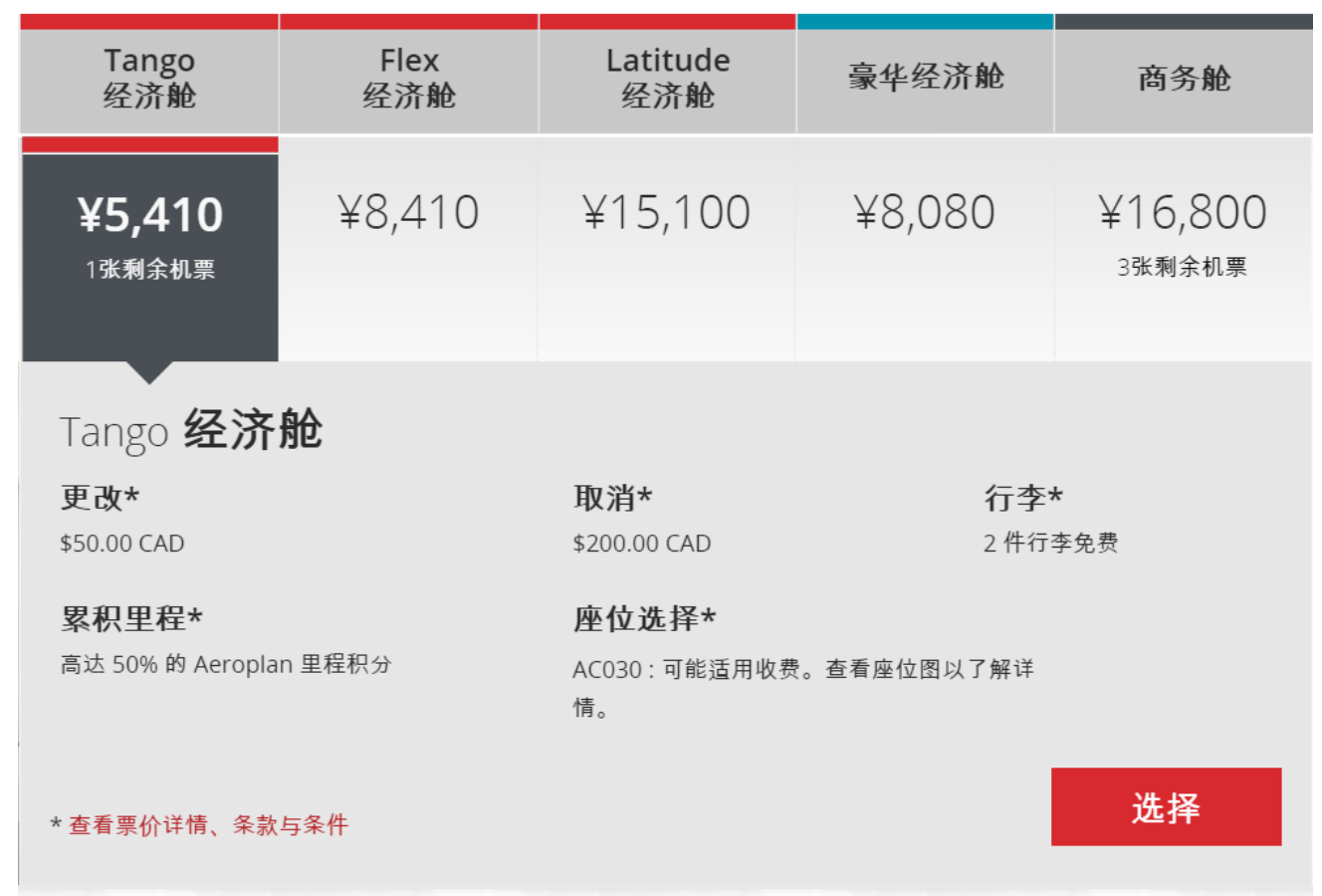

Figure 2. An example of "Internet product definition" by air Canada

From the searching results could be seen, Air Canada designed five products for passengers, which are economy class four subdivision product: Tango, Flex, Latitude, premium economy, as well as a business class product. Each product has different difference in price, changing rules and mileage accumulation. This product design thinking is designed from standing the passengers' view, which is what we call the customer-centered product design. Before the product design, of course, Air Canada needs identify its passengers in different groups will like what kind of the products, then stand in the perspective of passengers to designing the different products.

In addition, distributing the Internet channels. In the initial stage of airlines development, they mainly depended on the distribution channels. The agency found the passengers for the airlines and was responsible for selling the airline's products to passengers. Distribution is not just about distribution costs for airlines, but more importantly, airlines are losing their perception of the market. We might as well look at the airlines Internet from the perspective of the passenger, what is the passenger's demand on the sales channel? They want "to buy airline products and services 
everywhere, and to have a consistent experience in all sales channels." This is the normal demand of Internet users in the Internet age. Airlines do not need a simple distribution channel or direct channel marketing Strategy, but an omni-channel Strategy. The whole channel strategy includes direct selling, distribution, and also including online and offline sales. Its construction needs to recognize the aviation ecosphere in the tourism industry, and also considers that the airline is only one step of the whole aviation tourism industry. At the core of the all-channel strategy is planning the channels on the passenger experience around "centering on the passengers", which aims to capture as many potential passengers as possible in the whole channel.

Finally, building an internet IT system. Internet passengers, products, and channels, all around the "Centering on passengers" need to be supported by the customer-centric IT systems. According to the customer-centric thought, the author designs the overall architecture of the airline IT system, and the schematic diagram is as follows:

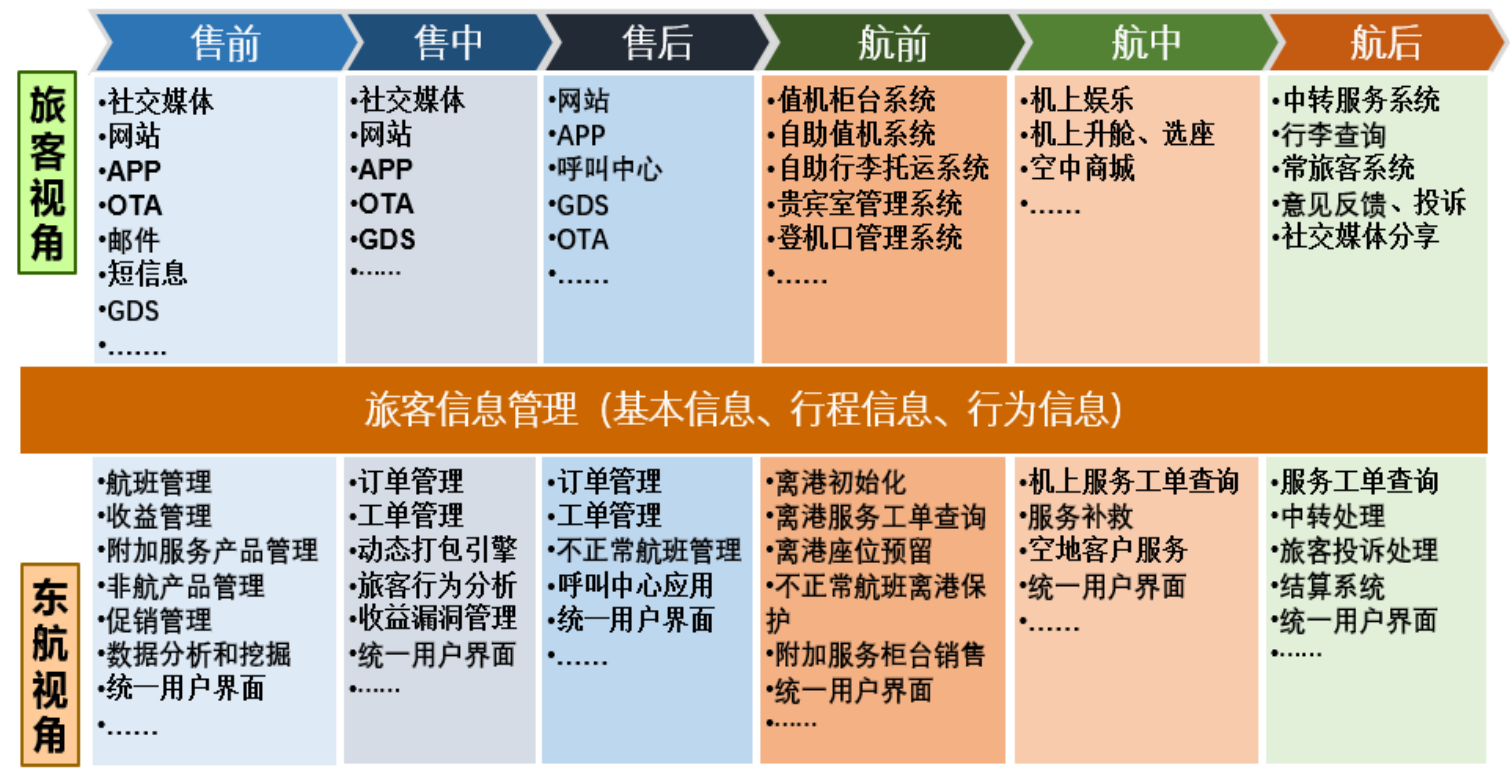

Figure 3. “customer-centric” IT architecture design idea

As shown in the figure, it analyzed is from the perspective of passengers and airlines. The analysis from the passenger's view ensures that the passenger's whole tour experience can be satisfied. From the perspective of airlines,it covers six main stages : pre-sale, sale, after-sale, pre-flight, flight and post-flight, which is an important guarantee for the company's earnings. At present, airlines are actively promoting the ancillary services sales, such as paying for seats, prepaying excess baggage fees and pre-selection meals. Airline products more and more rich, if wanting to develop a successful product, the airlines also need to stand in the perspective of passengers more to define their products, to build the product definition model around "Centering on the passengers". Only such products could make full use of the internet infrastructure to carry out sales and delivery, so as to help the airlines to become internet-oriented through the important pillar --- the products. The success of this method depends on how well we know the infrastructure of the Internet, and how well we know about the Internet passengers, products and channels.

In conclusion, the author roughly think of the airline Internet strategy, and think The fact of the airlines Internet is to replace, optimize and innovate the airline business process through the in-depth application of the Internet infrastructure. Airlines the real connotation of the Internet is, under the widely using in the social and economic Internet environment, the airline finish the joint with the Internet infrastructure environment at business operation principle, business processes, human resources, technical ability and so on various aspects, changing the traditional airline business that was existed before in-deep using the internet, to a new style airlines business with characteristics: efficient, collaborative, openness,employees self-drive, excellent passenger experience, growth the ancillary earning proportion in the internet ages. 


\section{Acknowledgements}

This research was financially supported by Civil Aviation Administration Safety Capacity Construction Projects 2017.

\section{References}

[1]. Qi Qi, Develop China Airport Economic Zone with Internet Spirit [N], China Civil Aviation Newspaper, 2014-8-12(1).

[2]. Qi Qi, Jian Ma, Innovation of Chinese Navigable Agroforestry Mode based on Internet Thinking[J], China Civil Aviation, 209(2015):27-28.

[3]. Qi Qi, Guangping Ji,Using the Technology of Internet of Things to Improve the Quality of Luggage Service [N], China Civil Aviation Newspaper, 2016-10-14(2).

[4]. Qi Qi, Standard Planning for Civil Aviation Industry - the Development Trend of Civil Aviation in China, Defense Industry Press, Beijing,

[5]. Yanhua, Li, Economic theory and practice of air transport, China Civil Aviation Press, Beijing, (04.2017) Reference to a chapter in an edited book:

[6]. Information on http://www.caac.gov.cn

[7]. Information on http://www.carnoc.com.cn 